\title{
RELATING 2-RAINBOW DOMINATION TO ROMAN DOMINATION
}

\author{
José D. Alvarado \\ Simone Dantas \\ Instituto de Matemática e Estatística \\ Universidade Federal Fluminense, Niterói, Brazil \\ e-mail: josealvarado.mat17@gmail.com \\ sdantas@im.uff.br \\ AND \\ Dieter RAutenbach \\ Institute of Optimization and Operations Research \\ Ulm University, Ulm, Germany \\ e-mail: dieter.rautenbach@uni-ulm.de
}

\begin{abstract}
For a graph $G$, let $\gamma_{R}(G)$ and $\gamma_{r 2}(G)$ denote the Roman domination number of $G$ and the 2-rainbow domination number of $G$, respectively. It is known that $\gamma_{r 2}(G) \leq \gamma_{R}(G) \leq \frac{3}{2} \gamma_{r 2}(G)$. Fujita and Furuya [Difference between 2-rainbow domination and Roman domination in graphs, Discrete Appl. Math. 161 (2013) 806-812] present some kind of characterization of the graphs $G$ for which $\gamma_{R}(G)-\gamma_{r 2}(G)=k$ for some integer $k$. Unfortunately, their result does not lead to an algorithm that allows to recognize these graphs efficiently.

We show that for every fixed non-negative integer $k$, the recognition of the connected $K_{4}$-free graphs $G$ with $\gamma_{R}(G)-\gamma_{r 2}(G)=k$ is NP-hard, which implies that there is most likely no good characterization of these graphs. We characterize the graphs $G$ such that $\gamma_{r 2}(H)=\gamma_{R}(H)$ for every induced subgraph $H$ of $G$, and collect several properties of the graphs $G$ with $\gamma_{R}(G)=\frac{3}{2} \gamma_{r 2}(G)$.
\end{abstract}

Keywords: 2-rainbow domination, Roman domination.

2010 Mathematics Subject Classification: 05C69.

\section{REFERENCES}


[1] J.D. Alvarado, S. Dantas and D. Rautenbach, Averaging 2-rainbow domination and Roman domination, Discrete Appl. Math. 205 (2016) 202-207. doi:10.1016/j.dam.2016.01.021

[2] J.D. Alvarado, S. Dantas and D. Rautenbach, Relating 2-rainbow domination to weak Roman domination, arXiv:1507.04899.

[3] B. Brešar, M.A. Henning and D.F. Rall, Rainbow domination in graphs, Taiwanese J. Math. 12 (2008) 213-225.

[4] M. Chellali, T.W. Haynes and S.T. Hedetniemi, Bounds on weak roman and 2rainbow domination numbers, Discrete Appl. Math. 178 (2014) 27-32. doi:10.1016/j.dam.2014.06.016

[5] M. Chellali and N.J. Rad, On 2-rainbow domination and Roman domination in graphs, Australas. J. Combin. 56 (2013) 85-93.

[6] S. Fujita and M. Furuya, Difference between 2-rainbow domination and Roman domination in graphs, Discrete Appl. Math. 161 (2013) 806-812. doi:10.1016/j.dam.2012.10.017

[7] I. Stewart, Defend the Roman empire!, Sci. Amer. 281 (1999) 136-139. doi:10.1038/scientificamerican1299-136

[8] Y. Wu and N.J. Rad, Bounds on the 2-rainbow domination number of graphs, arXiv:1005.0988v1.

[9] Y. Wu and H. Xing, Note on 2-rainbow domination and Roman domination in graphs, Appl. Math. Lett. 23 (2010) 706-709. doi:10.1016/j.aml.2010.02.012

Received 3 December 2015

Revised 7 July 2016

Accepted 8 August 2016 